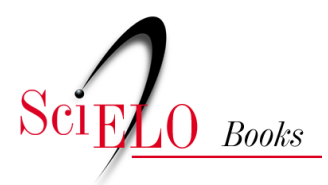

Parte II - Características e manifestações do modelo brasileiro: algumas reflexões

\title{
Análise do comportamento do desenvolvimento econômico e social dos municípios que compõem o COREDE Missões na década de 2000
}

\author{
Francisco Angst \\ Jorge Adalberto Schommer \\ Letiane Peccin Ristow \\ Micheli dos Santos
}

\section{SciELO Books / SciELO Livros / SciELO Libros}

ANGST, F., SCHOMMER, J.A., RISTOW, L.P., and SANTOS, M. Análise do comportamento do desenvolvimento econômico e social dos municípios que compõem o COREDE Missões na década de 2000. In: ROTTA, E., LOPES, H. C., and ROSSINI, N., eds. O modelo de desenvolvimento brasileiro das primeiras décadas do século XXI: aportes para o debate [online]. Chapecó: Editora UFFS, 2018, pp. 379-401. ISBN: 978-85-64905-82-5. https://doi.org/10.7476/9788564905832.0018.

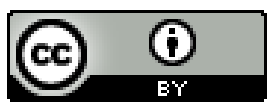

All the contents of this work, except where otherwise noted, is licensed under a Creative Commons Attribution 4.0 International license.

Todo o conteúdo deste trabalho, exceto quando houver ressalva, é publicado sob a licença Creative Commons Atribição 4.0.

Todo el contenido de esta obra, excepto donde se indique lo contrario, está bajo licencia de la licencia Creative Commons Reconocimento 4.0. 


\title{
ANÁLISE DO COMPORTAMENTO DO DESENVOLVIMENTO ECONÔMICO E SOCIAL DOS MUNICÍPIOS QUE COMPÕEM O COREDE MISSÕES NA DÉCADA DE 2000
}

\author{
Francisco Angst \\ Jorge Adalberto Schommer \\ Letiane Peccin Ristow \\ Micheli dos Santos
}

\section{INTRODUÇÃO}

Na década de 2000 o país passou por mudanças socioeconômicas que proporcionaram crescimento econômico e distribuição de renda. Em especial, ressalta-se o papel do conjunto de políticas públicas direcionadas à população mais pobre, que resultaram no aumento da renda per capitado trabalhador de US\$ 8.430,00, em 1994, para US\$11.150,00, em 2013, na redução da desigualdade, no qual o Índice de Gini passou de 0,601, em 1995, para 0,530, em 2012, e a redução do número de pessoas extremamente pobres caiu de 22,4 milhões para 10 milhões nesse período (IPEADATA, 2016).

Para acelerar o crescimento econômico e ter recursos para aperfeiçoar as políticas sociais, o governo federal desonerou os investimentos, a produção e o consumo através da renúncia de receitas tributárias. Isso vem ao encontro da estratégia de desenvolvimento adotada no Brasil, baseada em 
três frentes de expansão, na qual o país teria, através do consumo em massa, dos recursos naturais e da infraestrutura, os "motores do investimento", capazes de impulsionar a economia brasileira (BIELSCHOWSKY, 2014).

Segundo Fonseca (2004), o crescimento econômico tem sido consagrado como taxas positivas de crescimento do PIB, enquanto que desenvolvimento envolve melhoria dos indicadores sociais e consequente distribuição de renda. Esses dois conceitos, no entanto, não são antagônicos, haja vista que ambos se opõem à estagnação, no sentido de que ocorrem quando a economia cresce, possibilitando à sociedade reproduzir-se. Portanto, os ganhos de produtividade associados a um quadro institucional adequado para que o desenvolvimento e a redistribuição ocorram conjuntamente seriam o caminho para alcançar-se um desenvolvimento socialmente justo e equilibrado (FONSECA, 2004).

Muitos autores afirmam que durante a década de 2000, o contexto econômico mundial e as políticas públicas foram propícios para que ocorresse o desenvolvimento econômico e a distribuição de renda concomitantemente. Portanto, este estudo se propõe a verificar como se comportou a economia e o desenvolvimento dos municípios que fazem parte do COREDE Missões, Rio Grande do Sul (RS), diante das políticas desenvolvimentistas nacionais na década de 2000 , tendo em vista a importância regional desse conselho, que planeja mecanismos de participação social, para coletivamente encaminhar demandas congregadas de municípios pequenos, mas que contribuem substancialmente para o desenvolvimento do RS.Para isso, utilizaram-se os dados do Produto Interno Bruto (PIB) e do Valor Adicionado Bruto (VAB) dos segmentos agropecuária, indústria, administração pública e serviços, no período de 2000 a 2010 (IBGE, 2016). $\mathrm{Na}$ sequência, foi analisado se as políticas desenvolvimentistas promoveram a distribuição de renda entre a população dos municípios através do Índice de Gini, do percentual da população pobre e em extrema pobreza e o Índice de Desenvolvimento Humano Municipal (IDHM), disponível 
no Atlas do Desenvolvimento Humano no Brasil, nos anos de 2000 a 2010 (ATLAS BRASIL, 2016), abarcando, assim, sua evolução no período.

\subsection{Estado Desenvolvimentista}

No caso brasileiro, as políticas desenvolvimentistas constituíram-se em prática efetiva a partir de 1930, embora haja experiências regionais anteriores, com João Pinheiro em Minas Gerais e Getúlio Vargas no Rio Grande do Sul. Na literatura, é comum a referência ao "Nacional-Desenvolvimentismo" para designar o projeto varguista, mais nacionalista e com proposta de incorporação dos trabalhadores urbanos pela legislação trabalhista e previdenciária, e o "Desenvolvimentismo-Associado" ou "Internacionalizante" iniciado por Kubitschek e cuja consolidação teria ocorrido com os governos militares, após 1964.

Portanto, o conceito desenvolvimentista tem sua origem no processo histórico de superação a tendências de um Brasil marcado pela baixa produtividade, pelo desperdício de recursos, pela miséria, pelas disparidades regionais e pela dependência externa. Todavia, em um sentido mais amplo, o conceito propõe-se a captar um padrão de comportamento detectável à condução da ação estatal na esfera tecnológica, educacional, cultural e das políticas públicas. Em um sentido mais restrito, voltado à política econômica, propõe-se um projeto de longo prazo, centrado na industrialização e na modernização do setor primário, implementado com auxílio de medidas governamentais voltadas a incentivar a substituição de importações e a diversificação da produção primária, com prioridade ao mercado interno (FONSECA; CUNHA; BICHARA, 2013).

O livro intitulado Desenvolvimento Econômico e Desenvolvimento Político, de Hélio Jaguaribe, de 1962, é reconhecido como uma das primeiras obras a tratar desse tema. A partir daí, autores como Bresser-Pereira (1963) e Cardoso (1971) passaram a utilizá-lo; porém, foi na década de 70 que o termo teve seu uso difundido e vários autores buscaram 
conceituá-lo, alguns sob uma perspectiva ideológica e outros teóricos (FONSECA, 2014). Com base nesses dois grupos, Fonseca (2013) elencou três variáveis comuns que convergem para um núcleo do conceito de desenvolvimentismo: a existência de um projeto ou estratégia de nação; a intervenção consciente e determinada do Estado, a fim de viabilizar o projeto; e a industrialização como suporte ao crescimento econômico.

Sendo assim, a intervenção do Estado para o aumento da produtividade é o aspecto central da formulação de políticas desenvolvimentistas. Portanto, desenvolvimentismo é:

[...] a política econômica formulada e/ou executada, de forma deliberada, por governos (nacionais ou subnacionais) para, através do crescimento da produção e da produtividade, sob a liderança do setor industrial, transformar a sociedade com vistas a alcançar fins desejáveis, destacadamente a superação de seus problemas econômicos e sociais, dentro dos marcos institucionais do sistema capitalista (FONSECA, 2014, p. 59).

O modelo desenvolvimentista brasileiro ancorou-se em quatro pilares: no crescimento econômico impulsionado por mais emprego, crescimento real do salário-mínimo (de $\mathrm{R} \$ 381,36$, em dezembro de 2002, para R\$ 692,27, em dezembro de 2013) e pela redistribuição de renda salarial; pela implantação de um conjunto de políticas sociais a fim de consolidar um Estado de bem-estar social; pela expansão do crédito, com queda das taxas de juros, ampliação dos empregos formais e aumento real dos salários; e um conjunto de investimentos públicos diretos e indiretos (por meio de financiamentos) em infraestrutura e logística (CALIXTRE; BIANCARELLI; CINTRA, 2014).

Nesse sentido, desenvolvimentismo é quando no projeto nacional há a alocação de recursos para a transformação estrutural da economia, como ocorreu na década de 2000. Segundo Bielschowsky (2014), nessa década houve: crescimento com redistribuição de renda pela via do consumo de massa (Plano Plurianual 2004-2007); investimento em infraestrutura 
(Programa de Aceleração do Crescimento); e inovação (Política Industrial, Tecnológica e de Comércio Exterior, Programa de Desenvolvimento Produtivo e Plano Brasil Maior).

A distribuição de renda por si só não está associada ao desenvolvimentismo, pois, para que isso seja possível, ela precisaria estar associada a um projeto de industrialização e reestruturação produtiva em longo prazo (FONSECA, 2014). No Brasil, a distribuição de renda não se deu concomitante com tal projeto, uma vez que a base do crescimento econômico estava na geração de empregos e no aumento dos salários. Por isso, Fonseca, Cunha e Bichara (2013) afirmam que, para que houvesse ocorrido desenvolvimentismo efetivamente, seria preciso um consenso da natureza e da profundidade da política econômica, a fim de induzir investimentos em áreas prioritárias, conjuntamente com "ação estatal nas demais esferas de abrangência - como educação, tecnologia, mercado de trabalho e políticas sociais, dentre outras - de forma a forjar um projeto com coerência interna entre fins, meios e instrumentos para viabilizá-los” (p. 424).

\subsection{As três possíveis frentes de expansão da economia e o valor adicionado}

De acordo com a estratégia de desenvolvimento adotada, o Brasil tem três frentes de expansão (consumo de massa, recursos naturais e infraestrutura) que precisam ser incrementadas através da inovação tecnológica e de encadeamentos produtivos locais (turbinadores), as quais seriam capazes de promover a expansão da economia em longo prazo (BIELSCHOWSKY, 2014).

O consumo em massa representa para o país rendimentos em escala devido à dimensão de seu mercado interno, bem como progresso técnico e aumento da produtividade providos das estruturas produtivas e empresariais. Ademais, gera um círculo virtuoso: seu aumento provoca expansão dos investimentos, que, por sua vez, se traduz em aumento da produtividade 
e competitividade, as quais geram, através do lucro, aumento de salários das famílias que se transformam em consumo, o qual provoca aumento dos investimentos (BIELSCHOWSKY, 2014). O consumo em massa se dá tanto para produtos como para serviços.

Os recursos naturais são em abundância no país, seja terra, água, sol ou energias (elétrica, petróleo, etanol), os quais têm potencial de afirmação tecnológica nas áreas de produção e inovação em longo prazo. Entretanto, para que esse potencial seja eficiente, é preciso que seja produzida no país parte das máquinas e insumos, bem como se agregue valor em toda cadeia alimentar (BIELSCHOWSKY, 2014).

Já os investimentos em infraestrutura resultam na criação de empregos, geram externalidade ao setor privado e a toda a economia, por meio de efeitos de encadeamento e inovação transmitidos aos demais setores (BIELSCHOWSKY, 2014).

Em estudo recente, Bielschowski, Squeff e Vasconcelos (2014) analisaram empiricamente as principais tendências do investimento no Brasil na década de 2000, através da análise da Formação Bruta de Capital Fixo (FBCF) e sua relação com a evolução do valor adicionado e dos coeficientes de importação e exportação.

A FBCF é um indicador que mede o quanto as empresas aumentaram os seus bens de capital, que são os bens que geram outros bens. Através dele se identifica qual a capacidade de produção do país e se os empresários estão confiantes no futuro e se estão dispostos a investir (IPEA, 2016).

Dessa forma, quanto maior for a FBCF, maior é a capacidade de geração de Valor adicionado, que é o resultado da diferença entre os valores dos bens ou serviços após a transformação, durante o processo produtivo. É o que o agente econômico agrega de valor (MONTORO FILHO, 1992, apud PEREIRA, 2016).

Entre 2000 e 2008, o investimento da economia brasileira cresceu $4,8 \%$, enquanto que o valor adicionado cresceu apenas 3,2\% em relação ao PIB. Segundo Bielschowski, Squeff e Vasconcelos (2014, p. 141), esse 
aumento não se deu de forma homogênea no período, pois houve "declínio ou estagnação, nos anos de baixo crescimento (2000-2003); recuperação, junto com a economia (2003-2005); e forte expansão, bem superior ao crescimento do PIB, de 2005 a 2008”.

Com base no conceito de Valor Adicionado buscou-se analisar a dinâmica desta variável nos municípios do COREDE Missões.

\subsection{COREDE Missões}

Os Conselhos Regionais de Desenvolvimento (COREDEs), criados oficialmente pela Lei no 10.283 , de 17 de outubro de 1994, têm como objetivo a promoção do desenvolvimento regional harmônico e sustentável. Estão divididos em 28 conselhos, sendo que a região das Missões, do Noroeste do Rio Grande do Sul, integra o COREDE Missões, cuja localização encontra-se na Figura 1 (ATLAS SOCIOECONÔMICO DO RIO GRANDE DO SUL, 2016). 
Figura 1 - Localização dos municípios que compõem o COREDE Missões

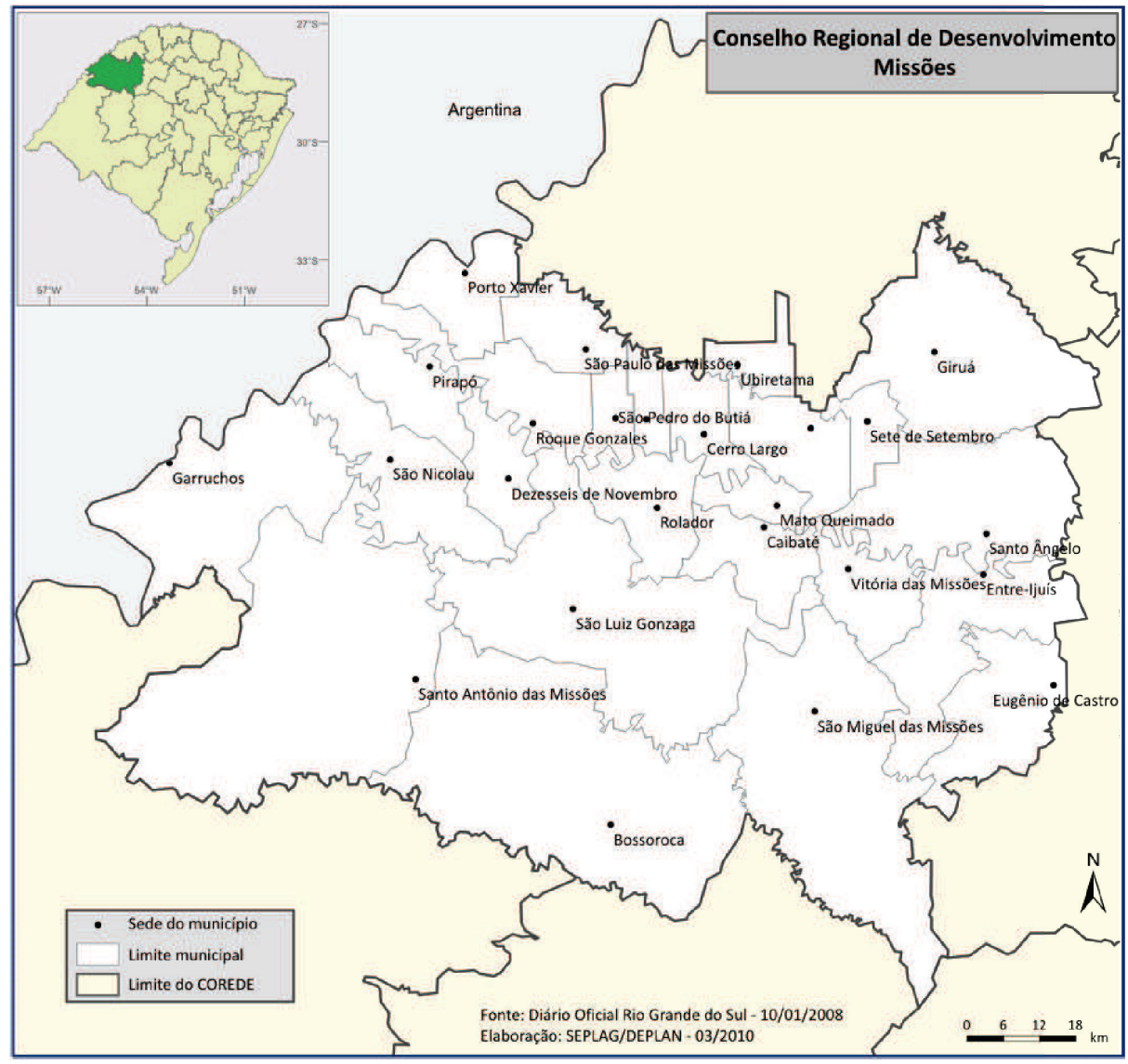

Fonte: FEE, 2016.

O COREDE Missões abarca 251.709 habitantes, distribuídos nos 25 municípios que o compõem: Bossoroca, Caibaté, Cerro Largo, Dezesseis de Novembro, Entre-ijuís, Eugênio de Castro, Garruchos, Giruá, Guarani das Missões, Mato Queimado, Pirapó, Porto Xavier, Rolador, Roque Gonzales, Salvador das Missões, Santo Ângelo, Santo Antônio das Missões, São Luiz Gonzaga, São Miguel das Missões, São Nicolau, São Paulo das Missões, São Pedro do Butiá, Sete de Setembro, Ubiretama, Vitória das Missões (FEE, 2016). 


\section{ANÁLISE DO DESEMPENHO DO COREDE MISSÕES NO PERÍODO DE 2000 A 2010}

\subsection{Análise do Valor Adicionado Bruto e do PIB do COREDE Missões}

Para verificar como se comportou a economia e o desenvolvimento dos municípios que fazem parte do COREDE Missões frente às políticas desenvolvimentistas nacionais, na década de 2000, analisou-se a evolução do Produto Interno Bruto (PIB) e do Valor Adicionado Bruto (VAB) dos segmentos agropecuária, indústria, serviços e administração pública, no período de 2000 a 2010, cuja evolução se encontra no Gráfico 1.

Gráfico 1 - Evolução do PIB e do VAB no COREDE Missões

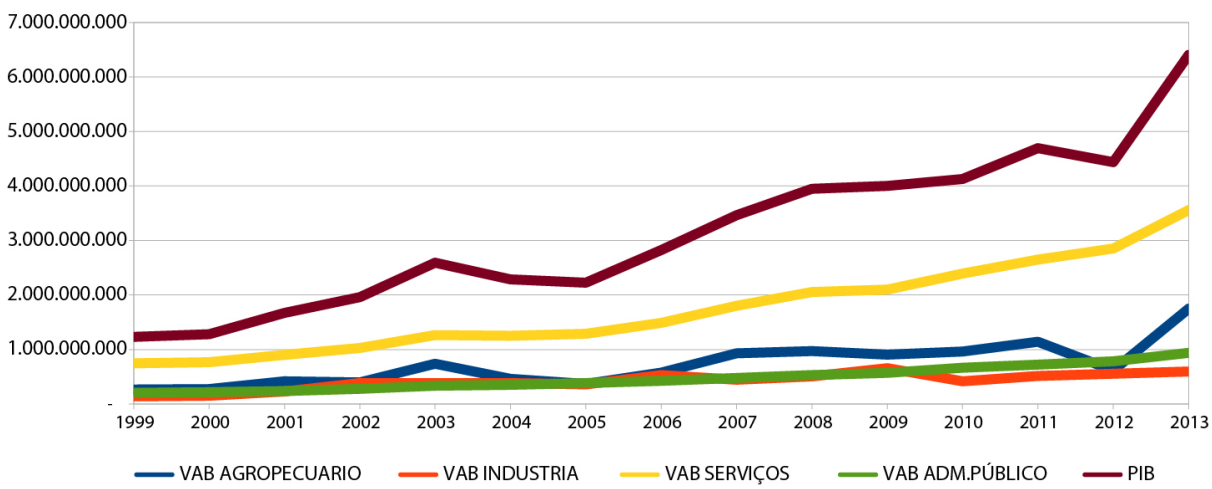

Fonte: Elaborado pelos autores, 2017.

Verifica-se que no COREDE Missões o PIB cresceu em torno de $20 \%$ no período, quando houve crescimento constante até 2003, decrescimento entre 2003 e 2005, e após esse período se recuperou, principalmente entre 2005 a 2008 e 2012 a 2013. O VAB Agropecuário, apesar de não obter a maior contribuição no PIB, comportou-se de maneira semelhante a ele, supondo-se que estão relacionados diretamente. Pode-se ainda verificar que entre os quatro segmentos analisados, é o VAB Serviços que possui maior participação no VAB Total; além disso, não apresentou quedas 
significativas nos períodos de decrescimento do PIB (2003 a 2005), mantendo crescimento estável em virtude da compensação promovida pela indústria e administração pública.

O COREDE Missões encontra-se em dificuldades, pois possui baixo crescimento do VAB e do emprego, inclusive menores que o crescimento da média estadual, o que lhe caracteriza com pouca competitividade especializada, indicando que sua estrutura produtiva deva ser redirecionada para setores mais dinâmicos (RIO GRANDE DO SUL, 2006).

Sendo assim, políticas públicas de médio e longo prazo para os municípios do COREDE Missões podem aumentar a participação do VAB Indústria e do VAB Administração Pública, para alavancar o VAB Serviços e garantir uma compensação de possíveis intempéries climáticas, nas quais o setor agropecuário é vulnerável, a fim de obter um crescimento estável.

Analisando separadamente o VAB Agropecuário apresentado no Gráfico 2, percebe-se que até o ano de 2003 houve expansão, com destaque para os anos de 2002-2003, quando houve crescimento acentuado; entretanto, o período de 2003-2005 foi marcado por um declínio na mesma proporção do crescimento dos anos anteriores. Já no período de 2005 a 2011, houve crescimento mais estável e contínuo; todavia, entre 2011-2012 apresentou-se o maior declínio em proporção a todo o período analisado. Em contrapartida, no ano seguinte houve rápida recuperação, passando de $\mathrm{R}$ \$ 600 milhões para quase R\$ 1,8 bilhões. Dessa forma, o VAB Agropecuário apresentou variações significativas no período, as quais implicaram diretamente no comportamento do PIB.

O Setor Agropecuário representa cerca de 36\% do PIB do COREDE Missões e possui produção predominante e crescente de soja, trigo, milho e mandioca, embora com produtividade abaixo da apresentada no Estado. Também há a produção de produtos considerados dinâmicos, como erva-mate, linho, amendoim e frutas (RIO GRANDE DO SUL, 2006). 
Gráfico 2 - Evolução do VAB Agropecuário do COREDE Missões

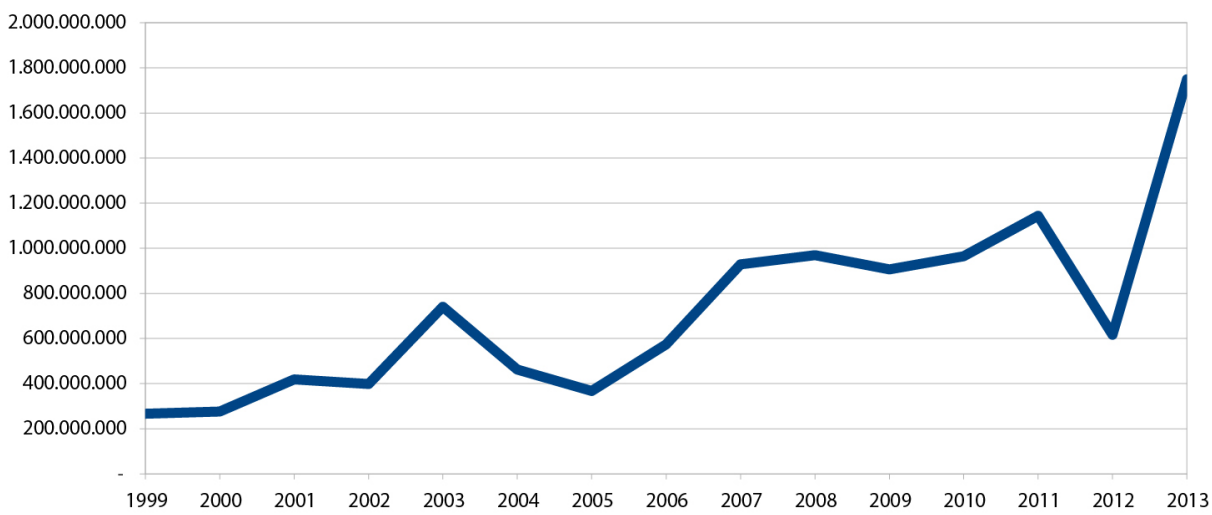

Fonte: Elaborado pelos autores, 2017.

No Gráfico 3 verificou-se primeiramente que, enquanto o VAB Agropecuário passou de $\mathrm{R} \$ 250$ milhões, em 1999, para quase $\mathrm{R} \$ 1,8$ bilhões, em 2013, o VAB Industrial apresentou crescimento no período, porém em proporção bem menor, passando de aproximadamente $\mathrm{R} \$ 150$ milhões para $\mathrm{R} \$ 600$ milhões.

Gráfico 3 - Evolução do VAB Indústria do COREDE Missões

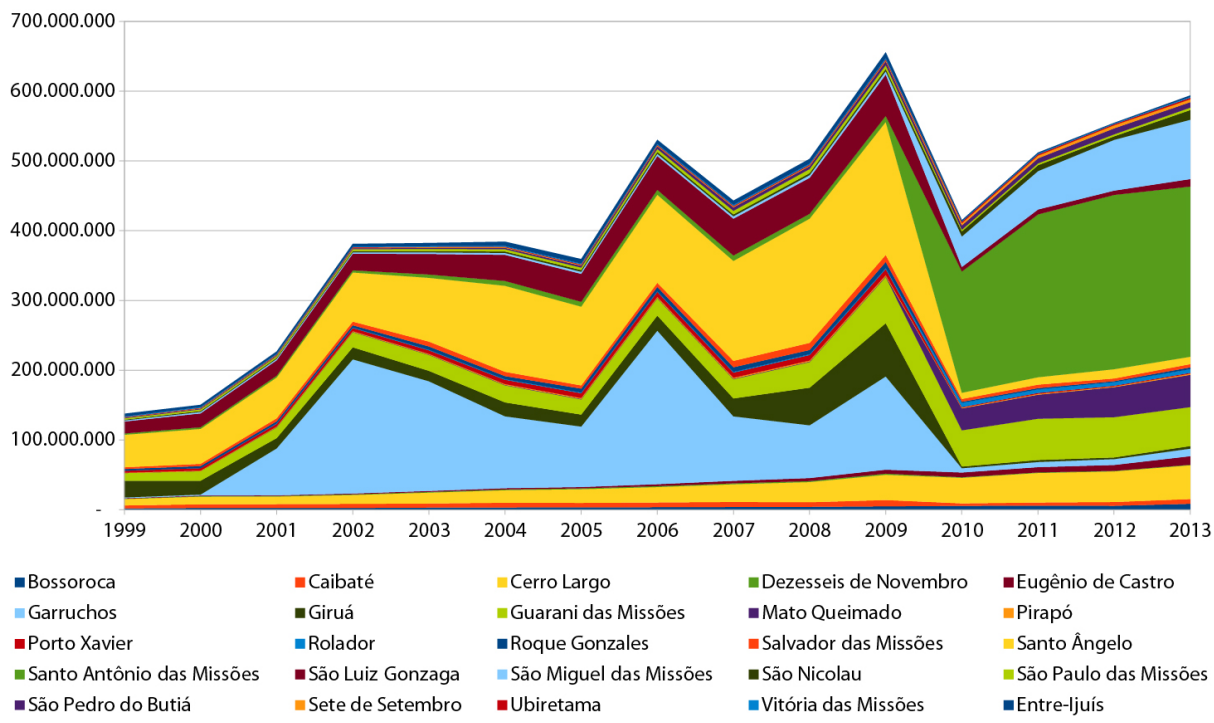

Fonte: Elaborado pelos autores, 2017. 
Percebe-se que houve uma queda acentuada do VAB Indústria nos municípios de Santo Ângelo e Garruchos nos anos de 2009 e 2010. Em contrapartida, o município de Santo Antônio das Missões teve elevado crescimento do VAB Indústria no mesmo período; entretanto, como não é objetivo deste estudo compreender as causas que levaram à situação específica desses municípios, cabe a trabalhos futuros investigá-las.

De acordo com o levantamento da Coordenação e Planejamento do Rio Grande do Sul, a indústria representa cerca de 10\% do PIB do COREDE, com indústrias de base agropecuária, como produtos de origem animal, óleos comestíveis e máquinas agrícolas. Há, ainda, produtos dinâmicos com alta taxa de crescimento nas áreas de tecnologias, siderúrgicos e químicos; entretanto, correspondem a apenas $4 \%$ do valor da produção regional do COREDE (RIO GRANDE DO SUL, 2006).

A seguir, analisou-se a evolução do VAB Administração Pública.

Gráfico 4 - Evolução do VAB Administração Púbica do COREDE Missões

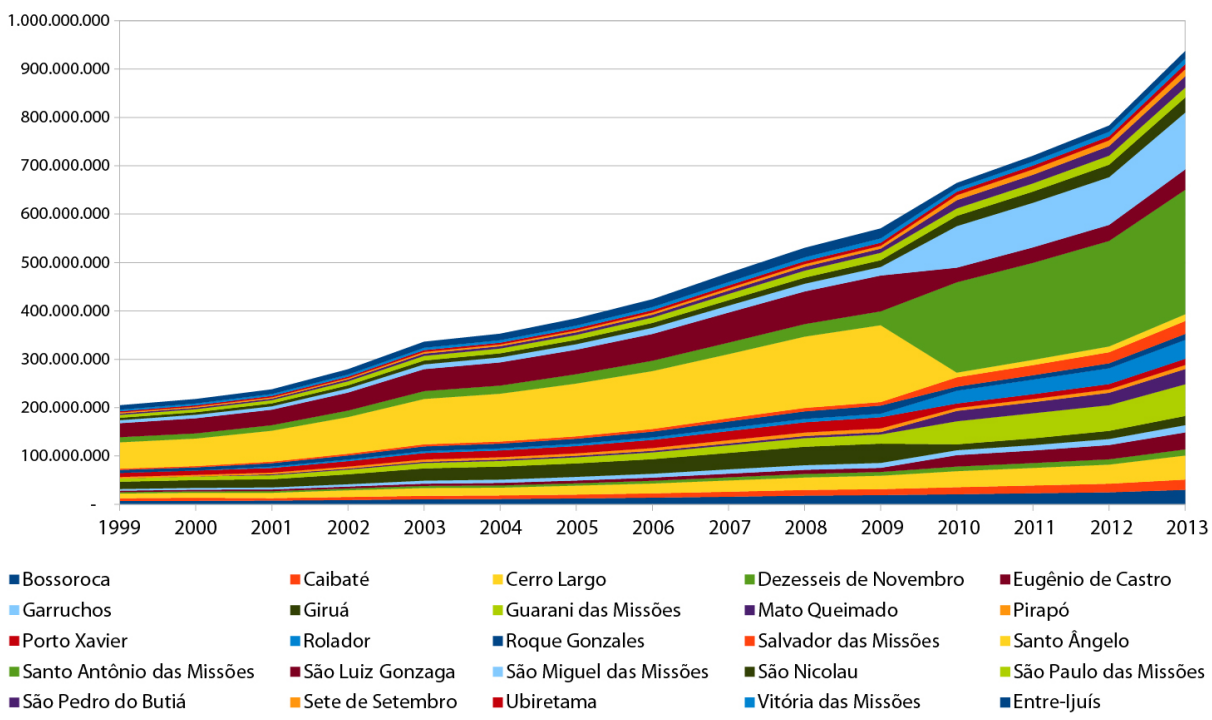

Fonte: Elaborado pelos autores, 2017.

Ocorreu crescimento exponencial do VAB da Administração Pública, principalmente a partir de 2005, partindo de aproximadamente $\mathrm{R} \$$ 
200 milhões, em 1999, para R\$ 900 milhões em 2013, de modo geral em todos os municípios, como pode se verificar no Gráfico 4. Em especial no período de 2010 a 2013, os municípios que obtiveram as maiores participações no VAB Administração Pública foram Santo Antônio das Missões e São Miguel das Missões.

Por fim, no Gráfico 5 analisa-se a evolução do VAB Serviços, o qual se manteve em crescimento estável e contínuo no período. Constatou-se que ele foi influenciado diretamente pelos outros três setores da economia local, de modo a equilibrar o VAB Total. Importante destacar que o crescimento no período foi de aproximadamente R $\$ 750$ milhões, em 1999, para aproximadamente $\mathrm{R} \$ 3,5$ bilhões, representando 55,52\% do PIB do COREDE Missões em 2013.

Gráfico 5 - Evolução do VAB Serviços do COREDE Missões

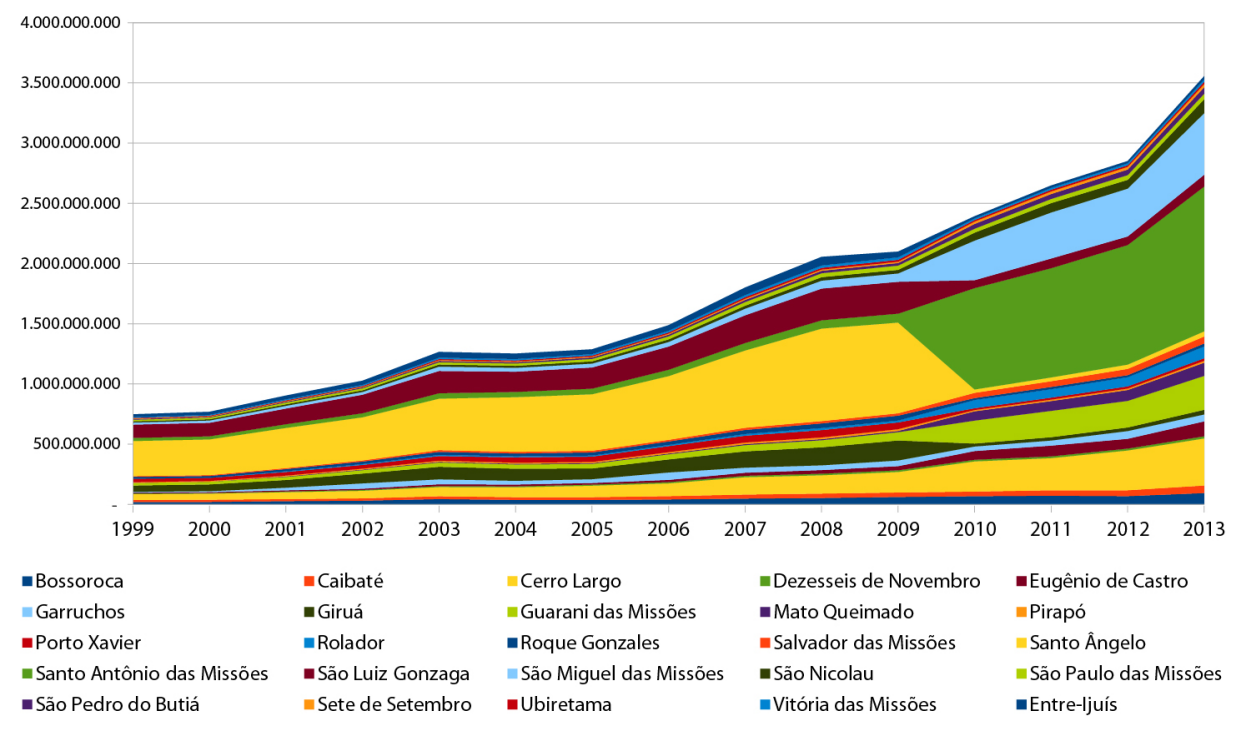

Fonte: Elaborado pelos autores, 2017.

Os municípios de Santo Antônio das Missões, São Miguel das Missões e Cerro Largo foram os que apresentaram maior crescimento do VAB Serviços ao longo do período analisado. Pode-se ainda verificar que 
o reflexo do que aconteceu no VAB da Indústria nos municípios de Santo Ângelo e Santo Antônio das Missões refletiu diretamente no VAB Serviços, os quais são visíveis nos Gráficos 3 e 4. De acordo com o levantamento, o setor de serviços e comércio é a base da estrutura produtiva do COREDE Missões, sendo responsável por 54\% do PIB regional (RIO GRANDE DO SUL, 2006).

Os principais fatores que colaboraram para o baixo desempenho do COREDE Missões são apontados no levantamento da Coordenação e Planejamento do Rio Grande do Sul: mercados locais pobres, pequenos e distante dos demais; movimentos oscilatórios das culturas agrícolas empresariais; movimentos migratórios expulsores de populações qualificadas; deficientes em infraestruturas; indicadores sociais médios; baixo empreendedorismo e atratividade; baixa geração de conhecimentos e inovações; baixos investimentos públicos e dificuldade de governança; mescla de potencialidades e restrições ambientais; e baixa governança (RIO GRANDE DO SUL, 2006).

\subsection{Análise da distribuição de renda no período}

A evolução dos valores do Valor Adicionado Bruto e Produto Interno Bruto ocorridos na década de 2000 geraram a queda da desigualdade de renda na população da grande maioria dos municípios do COREDE Missões, como se verifica no Gráfico 6, que demonstra, através do Índice de Gini, a diminuição de concentração de renda ocorrida no período.

O Índice de Gini é um instrumento que mede a concentração de renda e aponta a diferença entre os mais ricos e os mais pobres. Numericamente, ele varia de zero a um, sendo que zero significa uma situação de igualdade e um de desigualdades, onde há concentração de renda por poucos. Destacaram-se os municípios de São Miguel das Missões, Porto Xavier e Santo Antônio das Missões, que obtiveram a diferença no índice de 0,17, 
0,16 e 0,15 respectivamente. Em contraponto, verificou-se que no município de São Pedro do Butiá o processo foi inverso, pois houve concentração de renda no período, passando o Índice de Gini de 0,44 para 0,46. Os municípios de Vitória das Missões, Garruchos e Dezesseis de Novembro quase não tiveram alterações, nos quais a diferença do índice variou de 0,$01 ; 0,02$ e 0,02 respectivamente.

A queda da desigualdade de renda é importante, seja pela sua alteração em si, seja pela sua contribuição no aumento do poder de compra das famílias de menor renda (DEDECCA, 2014). Bielschowski, Squeff e Vasconcelos (2014) corroboram essa informação ao afirmar que quanto melhor for a distribuição de renda, mais potente será a frente de expansão da economia do mercado interno de consumo em massa.

Em nível nacional, a queda nas desigualdades sociais se deu conforme o Índice de Gini de 0,60 em 1991, para 0,53 em 2012. Apesar dessa queda expressiva, Dedecca (2014) ressalta que o país ainda possui um patamar elevado de desigualdade e, por isso, necessita de mobilização política pública para alcançar níveis próximos aos dos países desenvolvidos, pois a queda da desigualdade da distribuição da renda não foi suficiente pra que houvesse uma mudança estrutural do padrão de concentração existente. 
Gráfico 6 - Índice de Gini dos municípios do COREDE Missões entre 2000 a 2010

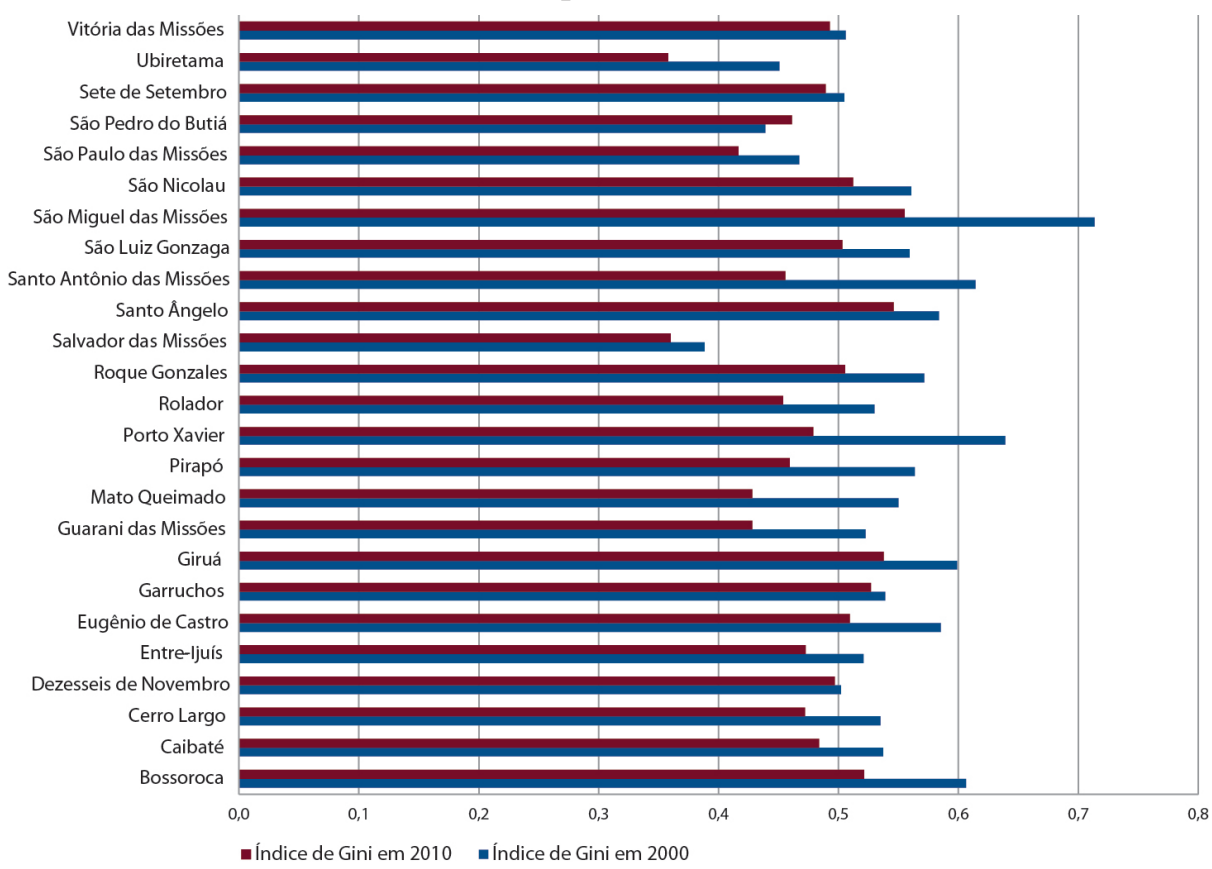

Fonte: Elaborado pelos autores, 2017.

Ao analisarmos mais detalhadamente a distribuição de renda nos municípios do COREDE Missões (Gráfico 7), verifica-se que os percentuais de população pobre e extremamente pobre tiveram grande redução no período. Os municípios de Pirapó e São Nicolau possuíam em 2000 os maiores percentuais de população extremamente pobre e foram estes municípios que, em 2012, obtiveram as maiores quedas, correspondendo 23,32\% e 17,89\%, respectivamente. Já o município de Salvador das Missões possuía em 2000 apenas 3,66\%, reduzindo para 0\% em 2010 sua população no nível de extrema pobreza. Semelhantemente, os municípios de Cerro Largo, São Pedro do Butiá e Ubiretama possuíam em 2010 menos de $1 \%$ de sua população em extrema pobreza. Entretanto, em 2010, os municípios de Dezesseis de Novembro, Garruchos e Vitória das Missões ainda possuíam em torno de $10 \%$ de sua população em extrema pobreza, vivendo com menos de 1,25 dólar por dia. 
Com relação aos percentuais da população pobre, também houve redução, destacando-se os municípios de Pirapó, Ubiretama, Santo Antônio das Missões e Bossoroca, que obtiveram redução de quase 30\% no período. Ressalta-se que, em 2010, os municípios de Pirapó, Vitória das Missões, Garruchos e São Nicolau possuíam em torno de 20\% da população em nível de pobreza.

Gráfico 7 - Percentuais de pobres e extremamente pobres nos municípios do COREDE Missões entre 2000 a 2010

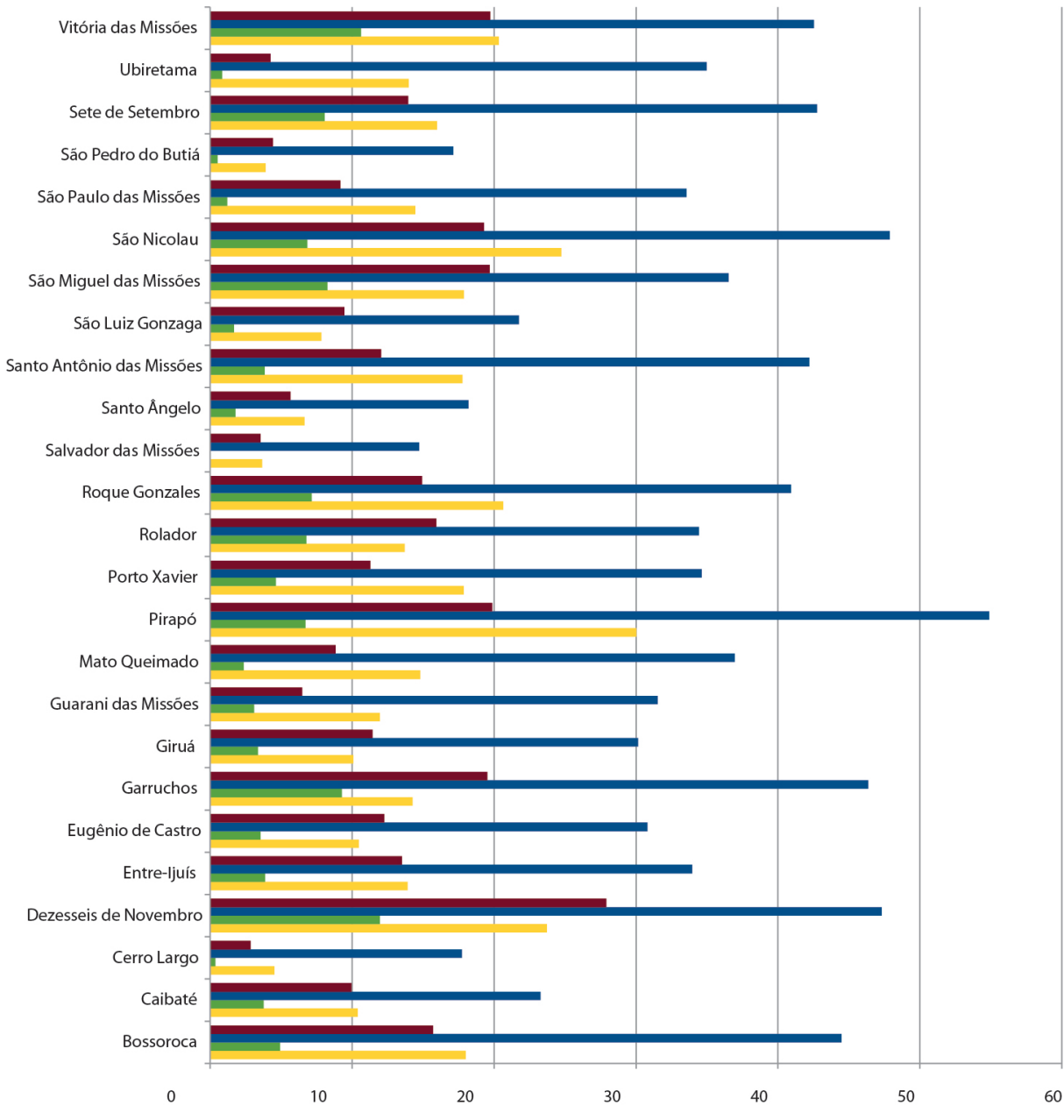


Entre os fatores que contribuíram para esse processo pode-se destacar que grande parte da distribuição de renda ocorrida no período se deu graças às políticas públicas de transferência de renda (Programa Bolsa Família) e de redução das taxas de desemprego, aliada ao bom desempenho da economia e recomposição dos níveis de rendimentos do trabalho (valorização salarial) (DEDECCA, 2014).

A população do COREDE Missões é uma das mais baixas rendas per capita do Estado e isso pode estar contribuindo, junto com outros fatores, para o arrefecimento da economia regional (RIO GRANDE DO SUL, 2006).

Todavia, como as medidas convencionais da pobreza podem não dar conta de situações das quais a população esteja sendo privada, como escolaridade, acesso à água e esgoto, é que analisamos o IDHM no COREDE Missões. O IDHM é um índice adaptado do IDH Global aos municípios, criado pelo PNUD Brasil, o Ipea e a Fundação João Pinheiro. Sua metodologia foi modificada em 2012 e considera as três dimensões: longevidade, educação e renda em nível municipal, a fim de avaliar o desenvolvimento destes. Sua medida varia de 0 a 1, sendo que quanto mais próximo de 1 , maior o desenvolvimento humano de um município (ATLAS BRASIL, 2016).

No Gráfico 8 verificamos que houve melhoria no IDHM de todos os municípios, destacando-se Sete de Setembro, Ubiretama e Guarani das Missões, que obtiveram os melhores desempenhos no período, sendo que em 2010 os municípios com melhor IDHM foram Santo Ângelo, Cerro Largo, São Pedro do Butiá e Salvador das Missões, correspondendo a 0,772, $0,764,0,763$ e 0,753 , respectivamente. 
Gráfico 8 - IDHM dos municípios do COREDE Missões entre 2000 a 2010

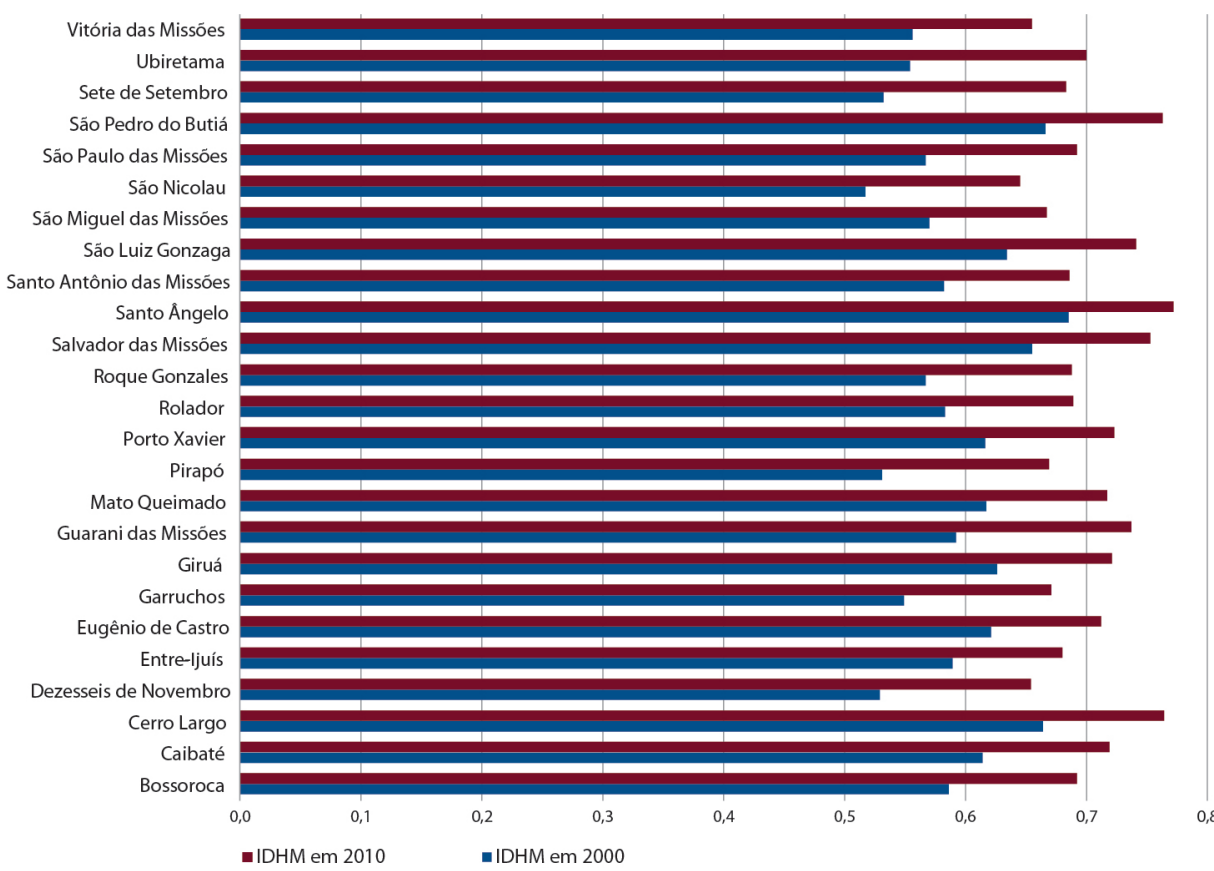

Fonte: Elaborado pelos autores, 2017.

Assim como no ranking dos municípios com maior percentual de pobreza e extrema pobreza, os municípios de São Nicolau, Dezesseis de Novembro, Vitória das Missões, Pirapó e Garruchos são os que possuem menores IDHM e, portanto, devem ter em suas políticas públicas priorizadas a melhoria da qualidade de vida de sua população.

\section{CONSIDERAÇÕES FINAIS}

A década de 2000 caracterizou-se por uma série de políticas públicas em nível nacional, que proporcionaram mudanças socioeconômicas com crescimento econômico e distribuição de renda, as quais foram caracterizadas por alguns autores como sendo ações desenvolvimentistas. Ao analisarmos a trajetória do COREDE Missões na década de 2000, verificamos 
que tais políticas em nível nacional não resultaram em alterações significativas nas estruturas produtivas e econômicas desses municípios, nos quais o PIB permaneceu centrado no setor de Serviços.

O VAB indústria corresponde a apenas 10\% do PIB do COREDE Missões, por isso, nas análises realizadas neste estudo, supõe-se que estímulos ao setor industrial não gerariam maior estabilidade ao PIB, em virtude de que ela não apresentou sazonalidade no período, comparado ao que ocorreu no VAB Agropecuária, que está relacionado às intempéries climáticas e à oscilação de preços dos produtos agrícolas. Além disso, o VAB Indústria interferiu diretamente no VAB Administração Pública, como observado nos municípios de Santo Ângelo e Santo Antônio das Missões.

O VAB Serviços é o que possuiu maior participação no PIB de todos os municípios do COREDE, além de ter apresentado crescimento estável e contínuo. O VAB Indústria, Agropecuária e de Administração Pública estiveram relacionados ao VAB Serviços, sendo que o comportamento de cada um refletiu no seu resultado.

Com relação às mudanças socioeconômicas do período, verificou-se que em todos os municípios houve redução das desigualdades de renda, dos percentuais de pobreza e extrema pobreza, bem como melhorias no IDHM. Há de ponderar-se que tais resultados foram diretamente influenciados pelas políticas distributivas realizadas pelo governo federal no período.

Este estudo preliminar permitiu supor que houve crescimento econômico, melhor distribuição de renda e melhorias nas condições de vida da população dos municípios do COREDE Missões, porém, reforça-se a necessidade de análise aprofundada em cada município, a fim de identificar os fatores que contribuíram para a trajetória de cada um deles.

\section{REFERENNCIAS}

ATLAS SOCIOECONÔMICO DO RIO GRANDE DO SUL. Conselhos Regionais de Desenvolvimento - COREDEs. Disponível em: $<$ http://www. 
atlassocioeconomico.rs.gov.br/conteudo.asp?cod_menu_filho=793\&cod_ menu=790\&tipo_menu=APRESENTACAO\&cod_conteudo $=1340>$. Acesso em: 09 jun. 2016.

ATLAS BRASIL. Atlas do desenvolvimento humano no Brasil. Disponível em: <www.atlasbrasil.org.b>. Acesso em: 14 jun. 2016.

BIELSCHOWSKY, R., Estratégia de desenvolvimento e as três frentes de expansão no Brasil: um desenho conceitual. In: CALIXTRE, A. B.; BIANCARELli, A. M.; CINTRA, M. A. M. (Ed.). Presente e futuro do desenvolvimento brasileiro. Brasília: IPEA, 2014, p. 115-133.

BIELSCHOWSKY, R.; SQUEFF, G. C.; VASCONCELOS, L. F. Evolução dos investimentos nas três frentes de expansão da economia brasileira na década de 2000. In: CALIXTRE, A. B.; BIANCARELLI, A. M.; CINTRA, M. A. M. (Ed.). Presente e futuro do desenvolvimento brasileiro. Brasília: IPEA, 2014, p. 135-194.

BRESSER-PEREIRA, L. C. O empresário industrial e a revolução brasileira, Revista de administração de empresas, São Paulo, v. 2, n. 8, p. 11-27, 1963.

CALIXTRE, A. B.; BIANCARELLI, A. M.; CINTRA, M. A. M. (Ed.). Presente e futuro do desenvolvimento brasileiro. Brasília: IPEA, 2014.

CARDOSO, F. H. Política e desenvolvimento em sociedades dependentes. Rio de Janeiro: Zahar Editores, 1971.

COREDE MISSÕES. Planejamento Estratégico da Região das Missões/ RS. Disponível em: <http://www2.al.rs.gov.br/forumdemocratico/LinkClick. aspx? fileticket $=9$ Urkjjeva2g\%3D\&tabid $=5363 \& \mathrm{mid}=7972>$. Acesso em: 09 jun. 2016.

DEDECCA. C. S. A redução da desigualdade e seus desafios. In: CALIXTRE, A. B.; BIANCARELLI, A. M.; CINTRA, M. A. M. (Ed.).Presente e futuro do desenvolvimento brasileiro. Brasília: IPEA, 2014, p. 469-512.

FONSECA, P. C. D. Desenvolvimento econômico e distribuição de renda. In: SALVO, Mauro e PORTO JR, Sabino da Silva. Uma Nova Relação entre Estado, Sociedade e Economia no Brasil. Santa Cruz do Sul: EDUNISC, 2004, v. 1, p. 269-292.

. Desenvolvimentismo: a construção do conceito. In: CALIXTRE, A. B.; BIANCARELLI, A. M.; CINTRA, M. A. M. (Ed.). Presente e futuro do desenvolvimento brasileiro. Brasília: IPEA, 2014, p. 29-78. 
FONSECA, P. C. D.; CUNHA, A. M.; BICHARA, J. S. O Brasil na Era Lula: retorno ao desenvolvimentismo? Nova Economia (UFMG. Impresso), v. 23, 2013, p. 403-428.

FUNDAÇÃO DE ECONOMIA ESTATÍSTICA (FEE). COREDE Missões. Disponível em:<http://www.fee.rs.gov.br/perfil-socioeconomico/coredes/ detalhe/?corede=Miss\%F5es $>$. Acesso em: 09 jun. 2016.

INSTITUTO BRASILEIRO DE GEOGRAFIA EESTATÍSTICA (IBGE). Cidades. Disponível em: <http://www.cidades.ibge.gov.br>. Acesso em: 14 jun. 2016.

INSTITUTO DE PESQUISA ECONÔMICA APLICADA (IPEA). Disponível em: <http://www.ipea.gov.br/desafios/index.php?option=com content\&id=2045: catid=28\&Itemid=23 $>$. Acesso em: 28 jun. 2016 .

. Laboratório de Ciência de Dados. (IPEADATA). Disponível em: $<$ http://www.ipeadata.gov.br/>. Acesso em: 14 jun. 2016.

PEREIRA, João Arami Martins. Um Estudo sobre Valor Adicionado e suas dificuldades de Acompanhamento no Município o Caso de Ijuí-RS. Site da Prefeitura de Ijuí/RS. Disponível em: <http://www.ijui.rs.gov.br/download/ baixar/65/304>. Acesso em: 28 jun. 2016.

RIO GRANDE DO SUL. Secretaria da Coordenação e Planejamento, Departamento de Estudos Econômicos e Sociais e Planejamento Estratégico. Rumos 2015: estudo sobre desenvolvimento regional e logística de transportes no Rio Grande do Sul. SCP/DEPLAN; DCAPET. Porto Algre: SCP, v. 5, 2006. 